\title{
Maintaining biodiversity in intensive grassland: Ground beetle communities in watercourse margins
}

D Madden $^{1,2}$, J Finn $^{1}$, S Harrison $^{2}$, D O hUallachain ${ }^{1}$

${ }^{1}$ Teagasc, Wexford, Ireland, ${ }^{2}$ University College Cork, Cork, Ireland

Email:donncha.madden@teagasc.ie

Introduction Riparian 'buffer' strips, i.e. linear stretches of vegetation next to a watercourse, are now widely used in agrienvironmental schemes as a means of reducing water pollution and increasing riparian biodiversity, however additional research into the effects they have on biodiversity is needed. Watercourse banks give the most protection from adjacent habitat conversion to semi-natural grassland plant species (Smart et al 2006). Watercourse margins are also important refuges for many invertebrate species (Matern et al. 2007). Currently, participants in REPS must fence all watercourse margins 1.5 metres from the stream edge. As no further management is required, these 'buffer' strips often succeed to later successional vegetation communities. A grazed watercourse margin, once fenced, and depending on a nearby source population, can quickly be colonised by bramble and/or gorse vegetation and subsequently by fast growing trees such as willow. The aim of this project is to study ground beetle assemblages within riparian 'buffer' zones in intensively managed grassland. We intend to identify the effects of riparian 'buffer' succession on ground beetle assemblages.

Material and methods Ten grassland-based REPS farms within Co. Wexford were selected for sampling. Within these farms a total of 30 fenced, riparian sampling locations were selected. Three sampling locations/plots $20 \mathrm{~m}$ in length were established on each farm, with each location allocated into one of three categories: Grassy sites (i.e. low herbaceous vegetation); scrubby sites (i.e. over $1.5 \mathrm{~m}$ vegetation, dominated by bramble and/or gorse) and woody sites (i.e. dominated by mature trees, willow, alder etc.). Pitfall traps were used to sample surface dwelling arthropods between early July and mid September within each vegetation category. Seven pitfalls were placed at each sampling location, giving 21 traps per farm and 210 in total. Traps were placed parallel to each stream, within $1 \mathrm{~m}$ of the bank edge and with $2 \mathrm{~m}$ between each trap, and invertebrates were removed every two weeks. Ground beetles from two 2-week sampling periods were identified to species level. Ground beetle assemblage data was analysed with Non-metric Multidimensional Scaling (NMDS) in PCORD and species richness and abundance data were analysed with ANOVA.

Results Over two 2-week sampling sessions from July and September 2008 a total of 1845 ground beetles consisting of 49 species were collected. Nineteen species were found in all three habitats. Seventeen species occurred in just one habitat, 14 of those in only one plot. Excluding species which occurred in only one plot (rare species), there were nine species which were not found in any wood plots and there were three species which were not found in grass plots. Only one species found in more than one plot was restricted exclusively to a particular habitat category, Bembidion guttula which was only found in scrub habitat on three farms. An ANOVA comparing trap mean species richness for plots in each habitat category did not reveal a significant difference between grass, scrub and wood plots (Table 1). Mean trap abundance was significantly different between different habitat categories (Table 1) with grass having the highest abundance. NMDS ordination showed no pattern of similarity for the same habitats on different farms. However on individual farms each habitat category provided species which were not recorded in either of the other two habitat categories (Table 1).

Table 4 Differences in abundance, species richness and number of unique species in each habitat

\begin{tabular}{llllll}
\hline \hline & Total & $\mathrm{F}_{2,54} ; \mathrm{P}$ & Grass & Scrub & Wood \\
\hline Abundance & 1845 & $4.09 ; 0.022^{*}$ & $6.95 \pm 1.176^{*}$ & $3.44 \pm 0.505^{*}$ & $4.65 \pm 0.830^{*}$ \\
Species & 49 & $0.984 ; 0.380^{*}$ & $1.19 \pm 0.080^{*}$ & $1.13 \pm 0.102^{*}$ & $1.02 \pm 0.084^{*}$ \\
Unique species & & $3.786 ; 0.029^{* *}$ & $3.42 \pm 0.428^{* *}$ & $2.58 \pm 0.467^{* *}$ & $1.79 \pm 0.355^{* *}$ \\
\hline \hline
\end{tabular}

* Trap Mean per plot \pm SE, ** Mean no. of species \pm SE found only that habitat

Conclusions Habitat categories did not show a significant difference in species richness. Plots from the same category on different farms did not show any pattern of similarity. Grass plots showed highest abundance but this was not unexpected, as these plots were part of a larger grass matrix i.e. within the grazed field. On average, each habitat category added unique species to the overall farm-scale riparian diversity of ground beetles. Lack of management subsequent to fencing can result in homogenisation of watercourse margin habitat with a dominance of one particular type of vegetation e.g. gorse scrub. It is important that agri-environment measures relating to watercourse margins take into account the need for habitat heterogeneity in order to provide a variety of habitat for species.

Acknowledgments This project was funded by the Department of Agriculture, Fisheries and Food under the National Development Plan 2006 Research Stimulus Fund.

\section{References}

Matern, A., Drees, C., Kleinwächter, M. and Assmann, T. 2007. Biological Conservation 136(4): 618-627.

Smart, S.M., Marrs, R. H., Le Duc, M.G., Thompson, K., Bunce, R. G. H., Firbank, L. G., Rossall, M. J. 2006. Journal of Applied Ecology 43(6): 1128-1137. 